\title{
Retractation note: Development of the radiant heating facilities for the testing of ceramic materials with operating temperatures up to $2000 \mathrm{~K}$
}

\section{Riza S. Baldzhiev, Pavel V. Prosuntsov and Maksim O. Zabezhailov}

Withdrawn article: MATEC Web of Conferences 298, 00111 (2019), https://doi.org/10.1051/matecconf/201929800111

Due to an unintentional misunderstanding between the authors and the guest editors of the conference, the above-mentioned article has been accidentally published in Web of Conferences. The publisher, the guest editors and the authors have therefore commonly decided to remove this article. 